\title{
Serum Procalcitonic (PCT) Versus Serum C - Reactive Protein (CRP) for Severity of Organ Dysfunction in Sepsis
}

\author{
Sirikonda Aishwarya ${ }^{\circledR 1}$, Karankoti Raj Kumar ${ }^{\circledR 2}$, Rallabhandi Sai Sri Harsha ${ }^{\circledR 3}$, Patnala Chakradhar ${ }^{\oplus 4}$ \\ ${ }^{1}$ Assistant Professor, Department of General Medicine, Gandhi Medical College, Secunderabad, Telangana, India, ${ }^{2}$ Post Graduate, Department of General Medicine, \\ Gandhi Medical College, Secunderabad, Telangana, India, ${ }^{3}$ Intern, Department of General Medicine, Gandhi Medical College, Secunderabad, Telangana, India, \\ ${ }^{4}$ Associate Professor, Department of General Medicine, Prathima Institute of Medical Sciences, Nagunoor, Karimnagar, Telangana, India.
}

\section{Abstract}

Background: Intensive care units (ICUs), despite advances in critical care nursing, have frequent issues with early diagnosis and adequate treatment. Recently discovered world-class procalcitonin (PCT), a revolutionary laboratory marker, has been shown to be useful in this regard. The objective is to Comparison of concentrations of serum procalcitonin (PCT) and c-reactive protein (CRP) with a comparable level of organ malfunction during sepsis and evaluation of the interaction between serum PCT and CRP concentrations with different organ malfunction occurrence in sepsis. Design: It is a Hospital-Based Prospective study. Participants and Setting: Fifty people were admitted to the intensive care unit of Gandhi Medical College. Subjects and Methods: The extent of sepsis-related organ impairment was evaluated with the sequential organ failure assessment (SOFA) on day 1. Patients were identified by category 1(0-6), category 2(7-12), group 3(13-18), and group 4(19-24) in 4 separate classes with varying organ impairment seriousness of sepsis. Serum PCT and CRP concentrations have been measured. Results: The majority of the patients belonged to the age groups of 60-69 years (30\%) and 50-59 years (22\%) Majority of the patients belonged to the Sofa group 1 around $42 \%$ followed by sofa group 2 with $38 \%$, sofa group 3 with $16 \%$ and the least belonged to the sofa group 4 with $4 \%$. The mean PCT and CRP concentration in those who survived was $14.73 \mathrm{ng} / \mathrm{ml}$ and $149.916 \mathrm{mg} / \mathrm{L}$ respectively and in those who died were $45.76 \mathrm{ng} / \mathrm{ml}$ ( $\mathrm{p}$-value $<0.001$ ) and $183.584 \mathrm{mg} / \mathrm{L}$ ( $\mathrm{p}$-value 0.172 ) respectively. The linear correlation between PCT plasma concentrations and the four groups was significantly stronger than with CRP. Conclusion: In SOFA and serum PCT, The level of organ dysfunction and complications in sepsis patients is closely related to serum CRP levels.

Keywords: SIRS (Systemic Inflammatory Response Syndrome), SOFA (Sequential Organ Failure Assessment), Sepsis, C - reactive protein (CRP), Procalcitonin (PCT)

Corresponding Author: Patnala Chakradhar, Associate Professor, Department of General Medicine, Prathima Institute of Medical Sciences, Nagunoor, Karimnagar, Telangana, India.

E-mail: drpatnalachakradhar@gmail.com

\section{Introduction}

A Greek phrase-putrid incorporates the name sepsis. Air touch and mortality were solely responsible for the putrefaction of a wound when the putrefaction cycle entered the blood (septicemia). PCT is not attributed to systemic bacterial diseases, respiratory illnesses, inflammatory and allergic conditions. It is not presently known if PCT is primarily affected by microbial inflammation of the extent of multiple organ dysfunctions due to systemic inflammatory reactions.

The criteria for the American College of Chest Physicists (ACCP) and the Society of Critical Care Medicines $(\mathrm{SCCM}),{ }^{[1]}$ defines sepsis as the incidence of documented or alleged infectious systemic inflammatory reaction syndrome with SIRS, ${ }^{[2,3]}$ (systemic inflammatory response syndrome) identified by the existence of $>2$ :

1) Heart rate $>90 / \mathrm{min}$

2) Respiratory rate $>20 / \mathrm{min}$ or $\mathrm{PaCO} 2<32 \mathrm{~mm} \mathrm{Hg}$

3) Body temperature $<36^{\prime} \mathrm{C}$ or $>38^{\prime} \mathrm{C}$

4) WBC Count $<4000$ or $>12000 / \mathrm{mm} 3$ or $>10 \%$ band forms(immature WBC's)

Sequential Organ Failure Assessment (SOFA) score has been established using systemic failure tests in six organ systems. ${ }^{[4]}$ (Respiratory, renal, kidney, coagulation and central nervous systems). Everyone is graded as 0 to 4 with an elevated frequency of impairment. Sepsis markers for both C-reactive protein (CRP) and procalcitonin (PCT) are recognized. 
Nonetheless, the link between plasma concentrations and septic intensity is still under debate. The plasma amounts of CRP and PCT in sepsis are also measured in a number of severities, as determined by the tests of the Couch.

\section{Subjects and Methods}

Type \& Place of study: It's a standardized retrospective study was conducted on 50 patients admitted to intensive care units at Gandhi Medical College.

\section{Inclusion Criteria}

Patient's $\geq 15$ years of age admitted to ICU.

\section{Exclusion Criteria}

1. Patients of age $<15$ years

2. Patients with post-operative and post-traumatic sepsis.

\section{Method of Collection of Data}

Patients chosen for the study are grouped into 4 categories depending on the extent of sepsis organ impairment according to the SOFA score.

- Group 1 0-6

- Group 2 7-12

- Group 3 13-18

- Group 4 19-24

Serum PCTand CRP concentrations were estimated in all the patients.

\section{Statistical Methods}

Statistical tables and charts were used to illustrate the statistical data. For statistical analysis, SPSS software version 20 was used.

\section{Results}

The majority of the patients belonged to the age groups of 6069 years $(30 \%)$ and $50-59$ years $(22 \%)$ and the least belonging to the age group of $15-29,30-39$ years both with $(8 \%)$ and Age of 80 years and above with $4 \%$.

The majority of the patients belonged to the Sofa group 1 around $42 \%$ followed by sofa group 2 with $38 \%$, sofa group 3 with $16 \%$ and the least belonged to sofa group 4 with $4 \%$.

Type of Infections seen in sepsis patients with the majority of the patients being diagnosed with Pneumonia around $42 \%$ of them followed by Urinary tract infection (UTI) seen in $22 \%$ of the patients with sepsis.

The mean PCT was more in SOFA group 4 around $87.71 \mathrm{ng} / \mathrm{ml}$ and it was least in group 1 around $7.237 \mathrm{ng} / \mathrm{ml}$. The mean CRP

\begin{tabular}{|lll|}
\hline \multicolumn{3}{|l|}{ Table 1: Age \& Sex Distribution } \\
\hline $\begin{array}{l}\text { Age Group } \\
\text { (Yrs.) }\end{array}$ & $\begin{array}{l}\text { Total No. of Patients } \\
(\mathbf{N}=50)\end{array}$ & Percentage $\%$ \\
\hline $15-29$ & 4 & $8 \%$ \\
\hline $30-39$ & 4 & $8 \%$ \\
\hline $40-49$ & 9 & $18 \%$ \\
\hline $50-59$ & 11 & $22 \%$ \\
\hline $60-69$ & 15 & $30 \%$ \\
\hline $70-79$ & 5 & $10 \%$ \\
\hline $80 \&$ above & 2 & $4 \%$ \\
\hline Sex & & \\
\hline Male & 29 & $58 \%$ \\
\hline Female & 21 & $42 \%$ \\
\hline
\end{tabular}

\begin{tabular}{|llll|}
\hline \multicolumn{5}{|c|}{ Table 2: SOFA Groups and Number of Patients } \\
\hline $\begin{array}{l}\text { Total } \\
\text { Sofa }\end{array}$ & $\begin{array}{l}\text { SOFA } \\
\text { Group }\end{array}$ & $\begin{array}{l}\text { Number of } \\
\text { patients }(\mathbf{n = 5 0})\end{array}$ & $\begin{array}{l}\text { Percentage } \\
\mathbf{\%}\end{array}$ \\
\hline $0-6$ & 1 & 21 & $42 \%$ \\
$9-12$ & 2 & 19 & $38 \%$ \\
$13-18$ & 3 & 8 & $16 \%$ \\
$19-24$ & 4 & 2 & $4 \%$ \\
\hline
\end{tabular}

Table 3: Infections are seen in Patients Belonging to Different SOFA Groups

\begin{tabular}{lll}
\hline Infection & $\begin{array}{l}\text { Number of patients } \\
(\mathbf{n = 5 0 )}\end{array}$ & $\begin{array}{l}\text { Percentage } \\
\mathbf{\%}\end{array}$ \\
\hline $\begin{array}{l}\text { Pneumonia tract } \\
\text { Urinary } \\
\text { infection (UTI) }\end{array}$ & 21 & $42 \%$ \\
\hline $\begin{array}{l}\text { Diarrhea } \\
\text { Pyogenic menin- } \\
\text { gitis }\end{array}$ & 6 & $22 \%$ \\
Cellulitis & 2 & $12 \%$ \\
\hline $\begin{array}{l}\text { Ludwig's angina } \\
\text { SBP }\end{array}$ & 1 & $8 \%$ \\
\hline $\begin{array}{l}\text { Dengue } \\
\text { Necrotizing fasci- } \\
\text { itis }\end{array}$ & 1 & $4 \%$ \\
Viral meningitis & 1 & $2 \%$ \\
\hline Malaria & 1 & $2 \%$ \\
\hline
\end{tabular}




\begin{tabular}{|c|c|c|c|c|c|c|}
\hline SOFA Score & SOFA Group & Total $(\mathrm{N}=50)$ & Percentage $\%$ & $\begin{array}{l}\text { Mean } \\
\text { (ng/ml) }\end{array}$ & PCT & Mean CRP (mg/L) \\
\hline $0-6$ & 1 & 21 & $42 \%$ & 7.237 & & 159.53 \\
\hline $7-12$ & 2 & 19 & $38 \%$ & 28.172 & & 155.23 \\
\hline $13-18$ & 3 & 8 & $16 \%$ & 43.23 & & 146.22 \\
\hline $19-24$ & 4 & 2 & $4 \%$ & 87.71 & & 41.73 \\
\hline
\end{tabular}

Table 5: Outcome Vs Mean Serum PCT and CRP Concentration

\begin{tabular}{lllll}
\hline Outcome & No. of patients & Percentage $\%$ & Mean PCT $(\mathbf{n g} / \mathbf{m l})$ & Mean CRP $(\mathbf{m g} / \mathbf{L})$ \\
\hline Survival & 41 & $82 \%$ & 14.73 & 149.916 \\
\hline Death & 9 & $18 \%$ & 45.76 & 183.584 \\
\hline Total & 50 & $100 \%$ & 21.89 & 155.332 \\
\hline
\end{tabular}

was least found in group 4 with $41.73 \mathrm{mg} / \mathrm{L}$ and highest in the group $159.53 \mathrm{mg} / \mathrm{L}$.

The survival rate of patients was $82 \%$ with mean PCT being $14.73 \mathrm{ng} / \mathrm{ml}$ and mean CRP being $149.916 \mathrm{mg} / \mathrm{L}$ in the survived patients. In patients who died around $18 \%$, the mean PCT was found to be $45.76 \mathrm{ng} / \mathrm{ml}$ and mean CRP was found to be $183.584 \mathrm{mg} / \mathrm{L}$.

With respect to outcome mean SOFA score and serum PCT $(\mathrm{ng} / \mathrm{ml})$ were higher with death than with survival (p-value $<0.001)$.

\section{Discussion}

The SOFA group mortality rate increased from group 1 to 4 indicating a higher mortality rate with serious and multiple organ dysfunction. SOFA and mean serum PCT concentrations were higher for SOFA (groups 3 and 4) than for patients with mild organ impairment (groups 1 and 2 of SOFA) in our sample $(\mathrm{p}<0.001)$. There was no statistically relevant difference in the concentration of mean serum CRP in the SOFA (organ dysfunction) classes. The mean SOFA score (organ dysfunction) was higher in patients who died than in those who had survived. $(\mathrm{p}<0.001)$. The mean PCT $(\mathrm{ng} / \mathrm{ml})$ serum concentration was higher for those who died than for surviving patients and the difference was statistically significant $(\mathrm{p}<0.001)$. Mean serum CRP $(\mathrm{mg} / \mathrm{L})$ concentration was not statistically relevant to the outcome. The positive association between the SOFA value and the mean PCT serum concentration was statistically important. There were no significant associations in our sample between the SOFA value and the mean PCT concentration. The findings of our analysis indicate that PCT rates were favorable for the extent of sepsis organ impairment as assessed by SOFA. The findings of our study are broadly compatible with studies that compared PCT levels with sepsis frequency with sepsis- related scoring systems. Previous tests demonstrated elevated rates of PCT and relatively small rates of SIRS or less serious systemic inflammation during a septic shock. Increased PCT concentrations were previously recorded during more extreme septic phases (serious sepsis / septic shock) as described in the ACCP / SCCM guidelines of Oberhofer et al, ${ }^{[5]}$ and Zeni et al. ${ }^{[6]}$ Al-Nawas et ${ }^{6},{ }^{[7]}$ registered very low PCT concentrations during SIRS, but high concentrations were found when septic shocks were detected. Gramm et.al, ${ }^{[8]}$ and de Werra et.al, ${ }^{\left[{ }^{[]}\right.}$showed identical findings. Such research does not evaluate the extent and intensity of sepsis and chronic inflammation with multiple organ failure. In a retrospective empirical analysis by Pugnani C et.al Castelli GP, PCT and SOFA were more likely to be higher in septic shock than extreme sepsis and sepsis. ${ }^{[10]}$ They found that PCT and SOFA were most directly linked to the extent of the infection. The results of our study are compatible with this statement. PCT has several advantages over CRP in severely ill sepsis patients. Concentrations of PCT are very weak in moderate organ impairment or bad systemic inflammatory reactions. Nevertheless, CRP levels are still strong for patients with higher SOFA concentrations. As a consequence, relative to PCT, CRP does not have useful statistics on the extent of organ dysfunction because the average rates of organ dysfunction have already been elevated during the more severe stage of the disease. Patients with low prognosis, i.e. patients with extreme organ failure (strong SOFA score) and those with sepsis have recorded elevated PCT rates. The key drawback of our research is the limited sample range in the classification of patients with extreme organ failure (SOFA classes 3 and 4). In comparison, organ impairment was not taken into consideration in the study of the association between serum PCT and CRP concentrations. In order to derive from the absolute amount of PCT concentrations to estimate the PCT prognosis, the number of patients in our study is very low to heterogeneous. 
Table 6: Comparison of study variables according to the outcome

\begin{tabular}{llll}
\hline Variables & Survival & Death & P-value \\
SOFA Score & $6.12 \pm 3.40$ & $11.03 \pm 4.51$ & $<0.001^{* *}$ \\
S.PCT $(\mathrm{ng} / \mathrm{ml})$ & $14.73 \pm 19.51$ & $45.76 \pm 37.01$ & $<0.001 * *$ \\
S.CRP $(\mathrm{mg} / \mathrm{L})$ & $149.91 \pm 56.41$ & $183.584 \pm 65.05$ & 0.172 \\
\hline
\end{tabular}

\section{Conclusion}

Patients with extreme organ dysfunction (SOFA group 3\&4) have a mean SOFA and PCT value greater than people with moderate organ dysfunction (SOFA group 1\&2) $(\mathrm{p}<0.001)$. The increase in the SOFA score was associated with a higher median value of PCT, but not of CRP. In patients who died of sepsis, the mean concentration of SOFA Score \& PCT was greater than that of survivors. Mean CRP was not substantially associated with the extent of the organ dysfunction/result. The ability of PCT to cause very significant volumes of serum during advanced phases of CRP-based modifications is characterized by its intensity while CRP is still already in its upper concentration range with small rates of SOFA.PCT and SOFA are strongly linked to the extent of the infection. PCT is easier than CRP to assess the frequency and prognosis of sepsis. Owing to the strong association between the PCT stage and the sepsis intensity and effect, the PCT diagnostic performance is superior to the CRP.

\section{References}

1. American College of Chest Physicians/Society of Critical Care Medicine Consensus Definition for sepsis and organ failure and guidelines for the innovative therapies in sepsis. Crit Care Med. 1992;20(6):864-874.

2. Rangel-Frausto MS, Pittet D, Costigan M, Hwang T, Davis CS, Wenzel RP. The Natural History of the Systemic Inflammatory Response Syndrome (SIRS). JAMA. 1995;273(2):117123. Available from: https://dx.doi.org/10.1001/jama.1995. 03520260039030.

3. Bone RC, Fisher CJ, Clemmer TP. Sepsis syndrome: A valid clinical entity. Crit Care Med. 1989;17(5):389-393.

4. Vincent JL, Ferreira F, Moreno R. Scoring Systems for Assessing Organ Dysfunction and Survival. Crit Care Clin. 2000;16(2):353-366. Available from: https://dx.doi.org/10. 1016/s0749-0704(05)70114-7.
5. Oberhofer M, Bögel D, Meier-Hellmann A. Procalcitonin is higher in non- survivors during the clinical course of sepsis, severe sepsis and septic shock. Intensive Care Med. 1996;22:245-245.

6. Zeni F, Viallon A, Assicot M. Procalcitonin serum concentrations and severity of sepsis. Clin Intense Care. 1994;5(2):89 98 .

7. Al-Nawas B, Krammer I, Shah PM. Procalcitonin in the diagnosis of severe infections. Eur J Med Res. 1996;1(7):331333.

8. Gramm HJ, Dollinger P, Beier W. Procalcitonin - einneuer Marker der inflammatorischenwirtsantwort. LongitudinalstudienbeiPatientenmit sepsis und Peritonitis. ChirGastroenterol. 1995;11(2):51-54. Available from: https://doi.org/10.1159/ 000189907.

9. de Werra I, Jaccard C, Corradin SB, Chiolero R, Yersin B, Gallati H, et al. Cytokines, nitrite/nitrate, soluble tumor necrosis factor receptors, and procalcitonin concentrations. Crit Care Med. 1997;25(4):607-613. Available from: https://dx.doi. org/10.1097/00003246-199704000-00009.

10. Castelli GP, Pognani C, Meisner M, Stuani A, Bellomi D, Sgarbi L. Procalcitonin and $\mathrm{C}$ - reactive protein during systemic inflammatory response syndrome, sepsis and organ dysfunction. Critical Care. 2004;8(4):234-242.

Copyright: (C) the author(s), 2020. It is an open-access article distributed under the terms of the Creative Commons Attribution License (CC BY 4.0), which permits authors to retain ownership of the copyright for their content, and allow anyone to download, reuse, reprint, modify, distribute and/or copy the content as long as the original authors and source are cited.

How to cite this article: Aishwarya S, Raj Kumar K, Sri Harsha RS, Chakradhar P. Serum Procalcitonic (PCT) Versus Serum C - Reactive Protein (CRP) for Severity of Organ Dysfunction in Sepsis. Acad. J Med. 2020;3(2):24-27.

DOI: dx.doi.org/10.47008/ajm.2020.3.2.6

Source of Support: Nil, Conflict of Interest: None declared. 